\title{
Exceptional molecular organization of canthaxanthin in lipid membranes*
}

\author{
Agnieszka Sujak \\ Department of Physics, University of Life Sciences in Lublin, Lublin, Poland
}

Canthaxanthin ( $\beta, \beta$-carotene $4,4^{\prime}$ dione) used widely as a drug or as a food and cosmetic colorant may have some undesirable effects on human health, caused mainly by the formation of crystals in the macula lutea membranes of the retina of an eye. Experiments show the exceptional molecular organization of canthaxanthin and a strong effect of this pigment on the physical properties of lipid membranes. The most striking difference between canthaxanthin and other macular pigments is that the effects of canthaxanthin at a molecular level are observed at much lower concentration of this pigment with respect to lipid (as low as $0.05 \mathrm{~mol} \%$ ). An analysis of the molecular interactions of canthaxanthin showed molecular mechanisms such as: strong van der Waals interactions between the canthaxanthin molecule and the acyl chains of lipids, restrictions to the segmental molecular motion of lipid molecules, modifications of the surface of the lipid membranes, effect on the membrane thermotropic properties and finally interactions based on the formation of the hydrogen bonds. Such interactions can lead to a destabilization of the membrane and loss of membrane compactness. In the case of the retinal vasculature, it can lead to an increase in the permeability of the retinal capillary walls and the development of retinopathy.

Key words: canthaxanthin, retinopathy, lipid membranes, molecular interactions

Received: 14 October, 2011; accepted: 01 March, 2012; available on-line: 17 March, 2012

\section{INTRODUCTION}

Canthaxanthin $\left(\beta, \beta\right.$-carotene $4,4^{\prime}$ dione $)$ is a carotenoid pigment widely distributed in nature. It is found in green algae, bacteria, crustaceans and fish. In the last 30 years it has been a popular E161g food additive and cosmetic colorant due to its very attractive color (Lober, 1985; Baker \& Gunther, 2004). There are many reports written on the undesirable health effects caused mainly by the formation of canthaxanthin crystals in the macula lutea membranes of the retina, associated with crystalline deposits of this pigment called canthaxanthin retinopathy (McGuinnes \& Beaumont, 1985; Daicker et al., 1987; Weber et al., 1987; White et al., 1988; Arden et al., 1989; Bopp et al., 1989). There is an increasing number of publications on other undesirable effects on human health arising from the use of this carotenoid, conditions such as retinal dystrophy (Hennekes, 1986) or aplastic anaemia (Bluhm et al., 1990). Canthaxanthin is frequently given to patients with tumours, as it can act as a strong antioxidant. Its anti-tumour and radical quenching action has been proven (Mayne \& Parker, 1989; Palozza et al., 1998; Chew et al., 1999). Experiments carried out on animals (Weber et al., 1987; Goralczyk et al., 2000) including humans (Boudreault et al., 1983; Macdonald et al., 1984; McGuinnes \& Beaumont, 1985; Daicker et al., 1987; Weber et al., 1987; White et al., 1988; Arden et al., 1989; Bopp et al., 1989) show that when used in small quantities (such as in food colouring or cosmetics) canthaxanthin can form molecular aggregates that are deposited in tissues especially in the macula lutea of the eye. The exact mechanism of canthaxanthin crossing the bloodbrain barrier and its delivery to the retina is still unclear. Some theories concerning macular pigments indicate their passive diffusion (Beatty et al., 2004), the role of cellular retinol-binding protein in this process (Bhosale \& Berstein, 2007) and the other assume that lipids play a role (Yeum \& Russell, 2002; Shafaa et al., 2007). Two key xanthophyll-binding proteins responsible for the uptake and stabilisation of macular carotenoids have been identified as GSTP1 (binding dietary zeaxanthin and non dietary meso-zeaxanthin) and StARD3 (dietary lutein) (Li et al., 2010; Li et al., 2011). The hypothesis was put forward that some specific properties of ocular carotenoids may be responsible for their presence in primate retinas (for review see: Subczynski et al., 2010). To understand why carotenoid pigment canthaxanthin forms toxic molecular aggregates with the macula lutea lipid membranes it is important to recognize the molecular mechanisms guiding its interactions. Since natural membranes are very composed structures, the usage of model lipid membranes composed of defined lipids is very useful in helping investigators to discern the specific cellular interactions. The question is how the membrane composition and structure affects the molecular organisation of canthaxanthin pigment, especially its orientation, aggregation process and distribution in the lipid membranes.

It has been proposed that the toxicity of canthaxanthin towards lipid membranes is the result of the strong interaction between the pigment and lipid molecules and of the formation of crystalline aggregates of canthaxanthin in the membranes (for review see: Sujak, 2009).

\section{OVERVIEW OF THE EXPERIMENTAL DATA}

Experiments carried out on model systems indicated an exceptional molecular organization of canthaxanthin in lipid membranes as well as a very strong effect of this

e-mail: agnieszka.sujak@up.lublin.pl

*Presented at the 16th International Symposium on Carotenoids, 17-22 July, 2011, Kraków, Poland

Abbreviations: DPPC, dipalmitoil phosphatidylcholine; EYPC, egg yolk phosphatidylcholine; FTIR, Fourier transform infrared absorption spectroscopy. 
carotenoid on the physical properties of the lipid membranes.

Interestingly, all the effects were observed at much lower concentrations of the pigment in the lipid phase (below $1 \mathrm{~mol} \%$; in some cases as low as 0.05 mol\%) than those of other xanthophylls such as lutein or zeaxanthin (for review on other carotenoids see: Gruszecki \& Strzałka, 2005). This can be the consequence of different structures of these macular carotenoids themselves (Bart \& MacGillavry, 1968; Linden et al., 2004). Apart from the functional keto-group in the ionone ring of canthaxanthin, the shape of the polyene chains in these xanthophylls differ to such an extent that this can affect their binding to the lipid membrane and the formation of molecular aggregates of xanthophyll molecules. The ends of the $\beta$-rings of canthaxanthin have dihedral angles of $43^{\circ}$, making it less probable that they will form a card-pack molecular aggregate, and increasing the likelihood of the formation of different types of aggregates. It also yields the possibility of contact with one polar surface, as in the case of lutein. The orientation angle of canthaxanthin in the lipid phase depend on the actual concentration of the pigment with respect to the lipid. The mean angle between the dipole transition moment and the axis normal to the plane of the DPPC membrane was determined as $20^{\circ}$ at $0.5 \mathrm{~mol} \%$. This confirmed a vertical orientation of the axis connecting opposite keto-groups of this xanthophyll at the 4 and $4^{\prime}$ positions. The angle of $47^{\circ}$ at $2 \mathrm{~mol} \%$ of canthaxanthin was measured, which implies the possibility that canthaxanthin incorporated into lipid membranes can be distributed in such a way that its small fraction can be oriented parallel to the plane of the lipid membrane. This indicated that canthaxanthin is similar to other macular pigment — lutein which parallel orientation has been proposed previously (Sujak et al., 1999; Sujak et al., 2005; Sujak, 2009); for review on other carotenoids see: Gruszecki, 2009.

Canthaxanthin toxicity towards the macula lutea lipid membranes can result from its very strong molecular interactions with the lipid molecules of different structures. Several of them are listed below.

1. Aggregation of canthaxanthin molecules in the lipid phase. The process of forming canthaxanthin aggregates in the lipid phase can not be easily monitored with the use of UV-Vis absorption as in the case of lutein and zeaxanthin (Sujak et al., 2000; Sujak et al., 2005). Aggregation is accompanied by a gradual decrease of the band representing the electronic transition between the ground energy level $\left({ }^{1} \mathrm{Ag}^{-}\right.$) and the $\mathrm{Bu}^{+}$state (main absorption maximum) and with its broadening (Sujak et al., 2005) but not to such scale that it would clearly account for the formation of H-type aggregates; J-type aggregates are rarely observed. This shows that aggregate formation may differ from that for lutein and zeaxanthin (Sujak et al., 2000).

2. Strong van der Waals interactions between the polyene chain of canthaxanthin and the lipid chains. Following series of diffraction, infra-red spectra and monolayer technique experiments it was concluded that canthaxanthin promotes the extended conformation of alkyl lipid chains (Sujak et al., 2005; Sujak et al., 2007b). Experiments showed the increase in thickness of the hydrophobic core of DPPC oriented bilayers supplemented with canthaxanthin. The same effect was observed previously for lutein (Sujak et al., 2002). The effect of removal of the semi-platean from isotherms of compression of the DPPC monolayer containing between 0.2 and $1 \mathrm{~mol} \%$ of canthaxanthin was observed even at relatively low surface pressure indicating the process of ordering of the hydrocarbon lipid chains.

3. Modifications of the lipid properties in the polar head zone. An analysis of the DPPC and EYPC small liposome size distribution profiles showed that canthaxanthin induces vesicle aggregation. Canthaxanthin caused the immobilization of the C-O-P-O-C and $\mathrm{PO}_{2}^{-}$groups (Sujak et al., 2005). ${ }^{1} \mathrm{H}-\mathrm{NMR}$ resonance experiments showed that canthaxanthin influenced the segmental molecular motion of DPPC lipid molecules both in the head-group region (the $\mathrm{N}^{+}\left(\mathrm{CH}_{3}\right)_{3}$ choline polar head-groups) and in the hydrophobic core of the bilayer (the $\mathrm{CH}_{2}$ and $\mathrm{CH}_{3}$ groups of the alkyl chains). The strongest immobilization of this part of the lipid molecules was observed at pigment concentrations between 1 and $1.5 \mathrm{~mol}^{\%}$ (Sujak et al., 2005) which can be the indication of the existence of the pigment aggregation threshold for these concentrations.

4. Changes in the thermotropic properties of lipid membranes. Like other macular xanthophylls, canthaxanthin changed the membrane thermotropic properties, but compared to lutein and zeaxanthin, the effect was much stronger (Castelli et al., 1999). The $50 \%$ decrease in the maximal value of the membrane molar heat capacity of DPPC multilammellar vesicles required $1-2 \mathrm{~mol} \%$ of lutein or zeaxanthin, while only $0.5 \mathrm{~mol} \%$ of canthaxanthin produced the same effect (Sujak et al., 2007a). The strongest influence of canthaxanthin on the main transition and pre-transition phases was observed on phosphocholines with the thinnest hydrophobic region. The observed disappearance of the pre-transition peak indicated fluidisation of the $\mathrm{L}_{\mathrm{b}}$. phase, as reported previously for other xanthophylls (Kolev \& Kafalieva 1986; KosteckaGugala et al., 2003). The effect of canthaxanthin was almost negligible in the case of lipids lacking the ester carbonyl groups. The shift of the main transition peak position towards higher temperatures $\left(\sim 3^{\circ} \mathrm{C}\right.$ at $0.1 \mathrm{~mol} \%$ of canthaxanthin) and narrowing of the pre-transition component, especially for canthaxanthin concentrations as low as $0.05 \mathrm{~mol} \%$ were registered which additionally accounted for the ordering effect of canthaxanthin on the lipid acyl chains. Based on Gaussian component analysis of the registered calorimetric signals, for all the kinds of lipids, formation of new thermotropic phases was observed (Sujak, et al., 2007a).

5. Interactions with the mediation of hydrogen bonds. It was shown that the behaviour of canthaxanthin strongly depends on the ability of the pigment molecules to form hydrogen bonds with the mediation of the canthaxanthin keto-groups located at the 4 and 4' positions either directly or indirectly via water molecules (Sujak et al., 2005).

The analysis of the FTIR spectrum of DPPC membranes containing $2 \mathrm{~mol} \%$ of canthaxanthin confirmed that these bonds can be created directly with the lipid ester carbonyl group or indirectly via water bridges using the keto-groups of canthaxanthin (Sujak et al., 2005). Additionally, the experiments show that the hydrophobic polyene of a carotenoid is able to carry water molecules bound by weak hydrogen bonds in which the water oxygen atom acts as a proton acceptor. It is also possible that water molecules can be bound to the polyene chain by weak hydrogen bonds with the $\pi$-conjugated doublebond system (Kupisz et al., 2008). This last mechanism may have a crucial significance in the formation of the 
molecular aggregates of canthaxanthin that may produce some undesirable health effects.

\section{CONCLUSIONS}

Geometry and properties of canthaxanthin can influence its transport to the macula lutea together with other macular carotenoids. It is probable that the strong interactions between canthaxanthin and lipid membrane determine the membrane behaviour, including its stability. Presence of this pigment within the lipid membranes and its unique organisation and interactions can lead to a destabilization of the membrane, resulting in the loss of membrane compactness. In the case of the retinal vasculature, it can lead to an increase in the permeability of the retinal capillary walls and the development of retinopathy.

\section{Acknowledgement}

Special thanks to Prof. Wiesław I. Gruszecki from the Department of Biophysics, Maria Curie-Sklodowska University in Lublin, Poland, where most of the experiments were carried out.

\section{REFERENCES}

Arden GB, Oluwole JO, Polkinghorne P, Bird AC, Barker FM, Norris PG, Haek JL (1989) Monitoring of patients taking canthaxanthin and $\beta$-carotene: an electroetinographic and ophtalmologic survey. Hum Toxicol 8: 439-450.

Baker R, Gunther C (2004) The role of carotenoids in consumer choice and the likely benefits from their inclusion into products for human consumption. Trends Food Sci \& Technol 15: 484-488.

Bart JC, MacGillavry CH (1968) The crystal and molecular structure of canthaxanthin. Acta Crystallogr B 24: 1587-1606.

Beatty S, Nolan H, Kavanagh O, O’Donovan (2004) Macular pigment optical density and its relationship with serum and dietary levels of lutein and zeaxanthin. Arch Biochem Biophys 430: 70-76.

Bhosale P, Bernstein PS (2007) Vertebrate and invertebrate carotenoidbinding proteins. Arch Biochem Biophys 458: 121-127.

Bluhm R, Branch R, Johnston P, Stein R (1990) Aplastic anaemia associated with canthaxanthin ingested for 'tanning' purposes. JAMA 264: 1141-1142.

Bopp S, el-Hifnawi EL, Laqua H (1989) Canthaxanthin retinopathy and macular pucker. J Fr Ophtalmol 12: 891-896.

Boudreault G, Cortin P, Corriveau LA, Rousseau AP, Tardif Y, Malenfant M (1983) Canthaxanthin retinopathy: 1. Clinical study in 51 consumers. Can J Ophtalmol 18: 325-328.

Castelli F, Caruso S, Giuffrida N (1999) Different effects of two structurally similar carotenoids, lutein and beta-carotene, on the thermotropic behaviour of phosphatidylcholine liposomes. Calorimetric evidence of their hindered transport through biomembranes. Thermochim Acta 327: 125-131.

Chew BP, Park JS, Wong MW, Wong TS (1999) A comparison of the anticancer activities of dietary $\beta$-carotene, canthaxanthin and astaxanthin in mice in vivo. Anticancer Res 19: 1849-1853.

Daicker B, Schiedt K, Adnet JJ, Bermond P (1987) Canthaxanthin retinopathy. An investigation by light and electron microscopy and physicochemical analysis. Graefes Arch Clin Exp Opbtalmol 222: 189197.

Goralczyk R, Barker FM, Buser S, Liechti H, Bausch J (2000) Dose dependency of canthaxanthin crystals in monkey retina and spatial distribution of its metabolites. Invest Ophthalmol Vis Sci 41: 1513-1522.

Gruszecki WI, Strzalka K (2005) Carotenoids as modulators of lipid membrane physical properties. Biochim Biophys Acta 1740: 108-115.

Gruszecki WI (2009) Carotenoids ion lipid membranes In: Physical chemical and Biological Function and Properties. Landrum JT, ed, pp 19-30. Taylor \& Francis Group, Boca Raton, London, New York.
Hennekes R (1986) Peripheral retinal dystrophy following administration of canthaxanthin? Fortschr Ophtalmol 83: 600-601.

Kolev VD, Kafalieva DN (1986) Miscibility of beta-carotene and zeaxanthin with dipalmitoylphosphatidylcholine in multilamellar vesicles: a calorimetric and spectroscopic study. Photobiochem Photobiophys 11: $257-267$.

Kostecka-Gugala A, Latowski D, Strzalka K (2003) Thermotropic phase behaviour of alpha-dipalmitoylphosphatidylcholine multibilayers is influenced to various extents by carotenoids containing different structural features-evidence from differential scanning calorimetry. Biochim Biophys Acta 1609: 193-202.

Kupisz K, Sujak A, Patyra M, Trebacz K, Gruszecki, WI (2008) Can membrane-bound carotenoid pigment zeaxanthin carry out a transmembrane proton transfer? Biochim Biophys Acta 1778: 2334-2340.

Li B, Vachali P, Frederick JM, Bernstein PS (2011) Identification of StARD3 as lutein-binding protein in the macula of the primate retina. Biochemistry 50: 2541-2549.

Li B, Vachali P, Bernstein PS (2010) Human ocular carotenoid-binding proteins. Photochem Photobiol Sci 9: 1418-1425.

Linden A, Bürgi B, Eugster CH (2004) Confirmation of the structures of lutein and zeaxanthin. Helvetica Chim Acta 87: 1254-1269.

Lober CW (1985) Canthaxanthin - the 'tanning' pill. J Am Acad Dermatol 13: 660 .

Macdonald K, Holti G, Marks J (1984) Is there a place for carotene/ canthaxanthin in photochemoterapy for psoriasis? Dermatologica 169: 41-46.

Mayne ST, Parker RS (1989) Antioxidant activity of dietary canthaxanthin. Nutr Cancer 12: 225-236.

McGuinnes R, Beaumont P (1985) Gold dust retinopathy after the ingestion of canthaxanthin to produce skin-bronzing. Med J 143: 622-623.

Palozza P, Maggiano N, Calviello G, Lanza P, Piccioni E, Ranelletti FO, Bartoli GM (1998) Canthaxanthin induces apoptosis in human cancer cell lines. Carcinogenesis 19: 373-376.

Shafaa MWI, Diehl HA, Socaciu C (2007) The solubilization pattern of lutein, zeaxanthin, canthaxanthin and $\beta$-carotene differ characteristically in liposomes, liver microsomes and retinal epithelial cells. Biophys Chem 129: 111-119.

Subczynski WK, Wisniewska A, Widomska J (2010) Location of macular xanthophylls in the most vulnerable region sof photoreceptor outer-segment membrane. Archives Biochem Biophys. 504: 61-66.

Sujak A, Gabrielska J, Grudzinski W, Borc R, Mazurek P, Gruszecki WI (1999) Lutein and zeaxanthin as protectors of lipid membranes against oxidative damage: the structural aspects. Arch Biochem Biophys 371: 301-307.

Sujak A, Gabrielska J, Milanowska J, Mazurek P, Strzalka K, Gruszecki WI (2005) Studies on canthaxanthin in lipid membranes. Biochim Biophys Acta 1712: 17-28.

Sujak A, Okulski W, Gruszecki WI (2000) Organisation of xanthophyll pigments lutein and zeaxanthin in lipid membranes formed with dipalmitoylphosphatidylcholine. Biochim Biophys Acta 1509: 255-263.

Sujak A, Mazurek P, Gruszecki WI (2002) Xanthophyll pigments lutein and zeaxanthin in lipid multibilayers formed with dimyristoylphosphatidylcholine. J Photochem Photobiol B 68: 39-44.

Sujak A, Strzalka K, Gruszecki WI (2007a) Thermotropic phase behaviour of lipid bilayers containing carotenoid pigment canthaxanthin: a differential scanning calorimetry study. Chem Phys Lipids 145: 1-12.

Sujak A, Gagos M, Dalla Serra M, Gruszecki WI (2007b) Organization of two-component monomolecular layers formed with dipalmitoylphosphatidylcholine and the carotenoid pigment, canthaxanthin. Mol Memb Biol 24: 431-444.

Sujak A (2009) Interactions between canthaxanthin and lipid membranes - possible mechanisms of canthaxanthin toxicity. Cell Mol Biol Lett 4: 395-410.

Weber U, Michaelis L, Kern W, Goerz G (1987) Experimental carotenoid retinopathy. II. Functional and morphological alterations of the rabbit retina after canthaxanthin application with small unilamellar phospholipid liposomes. Graefes Arch Clin Exp Ophtalmol 225: 346-450.

White GLJ, Beesley R, Thiese SM, Murdock RT (1988) Retinal crystals and oral tanning agents. Am Fam Physician 37: 125-126.

Yeum K-J, Russell RM (2002) Carotenoid bioavailability and Bioconversion. Annu Rev Nutr 22: 483-554. 